\title{
Treating chemical mechanical polishing (CMP) wastewater by electro-coagulation-flotation process with surfactant
}

\author{
C.Y. Hu ${ }^{\text {a, c }}$, S.L. Lo ${ }^{\text {a, c }}$, C.M. Li ${ }^{\text {a, c }}$, W.H. Kuan ${ }^{\text {b, c, } *}$ \\ ${ }^{a}$ Graduate Institute of Environmental Engineering, National Taiwan University, Chou-Shan Road, Taipei 106, Taiwan, ROC \\ b Department of Environmental and Safety Engineering, Ming-Chi University of Technology, 84, Gunjuan Road, Taishan, Taipei Hsien 243, Taiwan, ROC \\ ${ }^{\mathrm{c}}$ Research Center for Environmental Pollution Prevention and Controls Technology, National Taiwan University, Taiwan, ROC
}

Received 10 June 2004; received in revised form 28 November 2004; accepted 16 December 2004

\begin{abstract}
The effect of surfactants on the treatment of chemical mechanical polishing (CMP) wastewater by electro-coagulation-flotation (ECF) process was studied. Two surfactants, cetyltrimethylammonium bromide (CTAB) and sodium dodecylsulfate (SDS) were employed in this study to compare the effect of cationic (CTAB) and anodic (SDS) surfactants on ECF. The cationic surfactant can enhance the removal of the turbidity, but anodic surfactant cannot. It can be explained by the hetero-coagulation theory. Moreover, the addition of CTAB in CMP wastewater can reduce the sludge volume and the flotation/sedimentation time in ECF process. The residual turbidity and dissolved silicon dropped with the increase of charge loading. No CTAB pollution problem exists after the ECF process.
\end{abstract}

(C) 2005 Elsevier B.V. All rights reserved.

Keywords: Surfactant; Chemical mechanical polishing wastewater; Electro-coagulation-flotation process

\section{Introduction}

Chemical mechanical polishing (CMP) process is a conventionally adopted planarization technology in fabricating microchips for integrated circuit (IC) manufacturing [1]. The washing and cleaning step in CMP process consumes as much as $40 \%$ of the ultra-pure water used in semiconductor manufacturing and creates a large amount of wastewater $[2,3]$. The main contaminants in the CMP wastewater are the nano-sized $\mathrm{SiO}_{2}$ particles, dissolved silicon, dispersants/surfactants, oxidizing agents and heavy metal ions. Most of these pollutants can be effectively treated by coagulation using alum or other aluminum salts [1,2]. However, land requirement of the traditional coagulation process is extremely large because of the long retention time. Sufficient land for wastewater treatment is frequently unavailable for IC manufacturing in Taiwan, owing to the rapid growth of the IC production industry.

\footnotetext{
* Corresponding author. Tel.: +886 2 29089899x4653; fax: +886229041914 .

E-mail address: whkuan@ ccsun.mit.edu.tw (W.H. Kuan).
}

Therefore, new techniques with smaller land requirements are needed.

Electrochemical (EC) is a novel technique for treating wastewater [4-8]. Some studies have been successfully employed this process to treat CMP wastewater [9-11]. Al(III) ions and hydrogen gas are produced stoichiometrically and simultaneously when electric current passes through the aluminum electrodes (Eqs. (1) and (2)).

$$
\begin{aligned}
& \mathrm{Al}_{(\mathrm{s})} \rightarrow \mathrm{Al}_{(\mathrm{aq})}{ }^{3+}+3 \mathrm{e}^{-} \\
& 2 \mathrm{H}_{2} \mathrm{O}_{(\mathrm{l})}+2 \mathrm{e}^{-} \rightarrow 2 \mathrm{OH}_{(\mathrm{aq})}{ }^{-}+\mathrm{H}_{2(\mathrm{~g})}
\end{aligned}
$$

Tiny particles and other pollutants in CMP wastewater can be coagulated by $\mathrm{Al}(\mathrm{III})$ ions produced from anodes and then removed by flotation with hydrogen gas generated from cathodes. The flotation duration is markedly shorter than that of sedimentation following coagulation. Less land thus is required for the treatment plant. However, the particles cannot be completely removed by flotation in a conventional electro-coagulation-flotation (ECF) process because the solid loading of the wastewater is high and the collective 


\begin{tabular}{|ll|}
\hline \multicolumn{2}{|l|}{ Nomenclature } \\
\\
{$[\mathrm{CTAB}]$} & concentration of CTAB $\left(\mathrm{kg} \mathrm{m}^{-3}\right)$ \\
$F$ & Faraday constant $\left(F=96,487 \mathrm{C} \mathrm{mol}^{-1}\right)$ \\
$I$ & current $(\mathrm{A})$ \\
$n$ & cells number $(n=6$ in this paper $)$ \\
$P$ & atmosphere pressure $\left(\mathrm{N} \mathrm{m}^{-2}\right)$ \\
$Q_{\mathrm{e}}$ & charge loading $\left(\mathrm{C} \mathrm{m}^{-3}\right)$ \\
$R$ & ideal gas constant $\left(R=8.14 \mathrm{~J} \mathrm{~K}^{-1} \mathrm{~mol}^{-1}\right)$ \\
{$[\mathrm{Si}]_{\mathrm{D}}$} & concentration of dissolved $\mathrm{Si}\left(\mathrm{kg} \mathrm{m}^{-3}\right)$ \\
$t$ & reaction time $(\mathrm{s})$ \\
$T$ & temperature $(\mathrm{K})$ \\
$V$ & volume of the solution $\left(\mathrm{m}^{3}\right)$ \\
$V_{\mathrm{H}_{2}}$ & volume of the hydrogen gas $\left(\mathrm{m}^{3}\right)$ \\
$V_{\mathrm{S}}$ & volume of the sludge $\left(\mathrm{m}^{3}\right)$ \\
$Z$ & valence \\
& \\
\hline
\end{tabular}

efficiency of hydrogen gas is low. Most of the hydrogen bubbles generated from the cathode combine and then are lost to the air due to the hydrophobic nature of hydrogen gas.

Surfactants have been used to reduce bubble size and increase collective efficiency in the dispersed air flotation (DiAF) and dissolved air flotation (DAF) processes for a long time [12-15]. According to the hetero-coagulation theory, a small amount of surfactant $\left(10^{-7}-10^{-6} \mathrm{M}\right)$ in the solution can increase the contact angle, rupture the thin film and expand the three-phase-contact (TPC) between the gas and solid interface [16]. The expansion of the TPC perimeter produces a large contact area and a strong attachment force between the bubble and particle. This phenomenon can enhance the performance of flotation.

The retention time required for treating CMP wastewater by ECF can be dramatically reduced if adding surfactant enhances the performance of flotation of ECF. Therefore, two surfactants, cetyltrimethylammonium bromide (CTAB) and sodium dodecylsulfate (SDS), were employed to examine the influence of cationic and anionic surfactants on treating CMP wastewater by ECF process, respectively. After determining a suitable surfactant, the effects of the surfactant concentration and charge loading applied in the ECF process were investigated to optimize the operating parameters for treating the CMP wastewater.

\section{Experimental}

Experiments were conducted in a bipolar batch reactor with seven aluminum electrodes connected in parallel, as in the previous work by the same authors [8]. A constant current was maintained using a potentiostat in intensiostat mode. The volume of the solution $(V)$ of each batch was $1 \mathrm{~L}$. Magnetic stirring at $300 \mathrm{rpm}$ maintained a homogeneous solution in the batch reactor. The temperature in each system was maintained at $25 \pm 1{ }^{\circ} \mathrm{C}$.

Wastewater was sampled from a semiconductor manufacturer in south Taiwan. A measured amount of CTAB or SDS stock solution was added to the wastewater as a collector and frother. A suitable quantity of $\mathrm{NaCl}\left(50 \mathrm{mg} \mathrm{L}^{-1}\right)$ was added to the wastewater to increase the wastewater conductivity from 134 to $273 \mu \mathrm{S} \mathrm{cm}^{-1}$. Samples were taken at certain time intervals following the completion of the ECF process to examine the retention time required for floc floating or sediment. The certain time intervals following the completion of the ECF process was defined as the "flotation/sedimentation time". Except the pre-test of the effect of surfactant types and the effect of flotation/sedimentation time on the residual turbidity, $30 \mathrm{~min}$ was chosen as the flotation/sedimentation time in the rest of the experiments. Water qualities, such as turbidity (in terms of Nephelometric turbidity unit (NTU), HACH, 2100P), suspended solids (SS), total solids (TS), $\mathrm{pH}$, total organic carbon (TOC, O.I. Analytical, 1010) and conductivity before and after the ECF process, were measured using standard methods. Moreover, concentrations of dissolved $\mathrm{Si}$ and other heavy metals were measured by an inductively coupled plasma atomic emission spectrophotometer (ICP-AEC, Model JY24, Jobinyvon). Finally, a zeta potential analyzer (Model Zetasizer 3000, Malvern Instrument Ltd., Worcester, UK) was used to determine the zeta potential and particle size distribution before and after the ECF reaction.

The sludge sedimentation/flotation tests were conducted by a Pyrex glass column of $45 \mathrm{~cm}$ high and $5.85 \mathrm{~cm}$ i.d. as used in Lai and Lin's work [11]. After the ECF process, $1 \mathrm{~L}$ of the treated CMP wastewater was put in the column with well mixed. After the separation of sludge and liquid was completed $(30 \mathrm{~min})$, the ratio of the height of the sludge and the height of solution was the sludge percentage of the solution $\left(V_{\mathrm{s}} / V\right)$.

\section{Results and discussion}

\subsection{Properties of CMP wastewater}

Table 1 lists the water quality of the CMP wastewater in this work and in Chen and Lin's work [10]. The total solids in both of the wastewater were extremely high but the suspended solids were very low. This phenomenon was due to the tiny particle size of the silica particle. The pore size of the standard filter paper for SS is $0.45 \mu \mathrm{m}$, which is much larger than the average particle size. Thus, most of the particles pass though the filter and cannot be measured. The copper concentration and TOC in this work were much lower than those in Chen and Lin's work. This phenomenon may occur because of the different processes used by the two different semiconductor manufacturers. Notably, the concentration of dissolved $\mathrm{Si}$ in the wastewater was extremely high. The dissolved $\mathrm{Si}$ is also a problem requiring resolution for $\mathrm{CMP}$ wastewater reuse. High concentrations of dissolved Si may 
Table 1

Water quality and properties of the CMP wastewater in this work and in Chen and Lin's work

\begin{tabular}{|c|c|c|}
\hline \multirow[t]{2}{*}{ Parameter } & \multicolumn{2}{|c|}{ Concentration or properties } \\
\hline & This work & Chen and Lin's work \\
\hline $\mathrm{pH}$ & 8.5 & $6-8.7$ \\
\hline Turbidity (NTU) & 155 & - \\
\hline $\mathrm{TS}\left(\mathrm{mg} \mathrm{L}^{-1}\right)$ & 2403 & $4000-5000$ \\
\hline $\mathrm{SS}\left(\mathrm{mg} \mathrm{L}^{-1}\right)$ & 37.5 & $0.1-0.4$ \\
\hline Total $\mathrm{Si}\left(\mathrm{mg} \mathrm{L}^{-1}\right)$ & 1406 & - \\
\hline Dissolved $\mathrm{Si}\left(\mathrm{mg} \mathrm{L}^{-1}\right)$ & 253 & - \\
\hline Solid Si $\left(\mathrm{mg} \mathrm{L}^{-1}\right)$ & 1171 & - \\
\hline Average particle size (nm) & 79.8 & 100 \\
\hline Zeta potential $(\mathrm{mV})$ & -45.5 & - \\
\hline $\mathrm{TOC}\left(\mathrm{mg} \mathrm{L}^{-1}\right)$ & 1.81 & $79-180^{\mathrm{a}}$ \\
\hline Conductivity $\left(\mu \mathrm{S} \mathrm{cm}^{-1}\right)$ & 148 & $450-470$ \\
\hline $\mathrm{Al}\left(\mathrm{mg} \mathrm{L}^{-1}\right)$ & 2.15 & - \\
\hline $\mathrm{K}\left(\mathrm{mg} \mathrm{L}^{-1}\right)$ & 61.6 & - \\
\hline $\operatorname{Mn}\left(\mathrm{mg} \mathrm{L}^{-1}\right)$ & 0.38 & - \\
\hline $\mathrm{Zn}, \mathrm{Pb}, \mathrm{Fe}, \mathrm{Ag}, \mathrm{Mn}, \mathrm{Cu}\left(\mathrm{mg} \mathrm{L}^{-1}\right)$ & ND & $45-120$ for $\mathrm{Cu}^{2+}$ \\
\hline
\end{tabular}

${ }^{a}$ Transformation from COD data $(210-480 \mathrm{mg} / \mathrm{L}$ as COD).

cause membrane fouling in the reverse osmotic (RO) process during the regeneration of ultra-pure water from the treated wastewater.

\subsection{Effects of surfactants}

Fig. 1 shows that adding CTAB enhanced the removal of the turbidity, but SDS did not. This fact should be due to the electrostatic induction between the bubbles and particles. When the bubbles are surrounded by the surfactants, the cationic surfactants, such as $\mathrm{CTAB}$, produce positivecharged bubbles and the anodic surfactants, such as SDS, produce negative-charged bubbles. As mentioned earlier, the particles in CMP wastewater are strongly negatively charged. Therefore, when the cationic surfactants were added, an electrostatic induction occurred between the bubbles and particles. This induction force stabilized the mixture of bubbles and particles; otherwise, the mixture was unstable. This

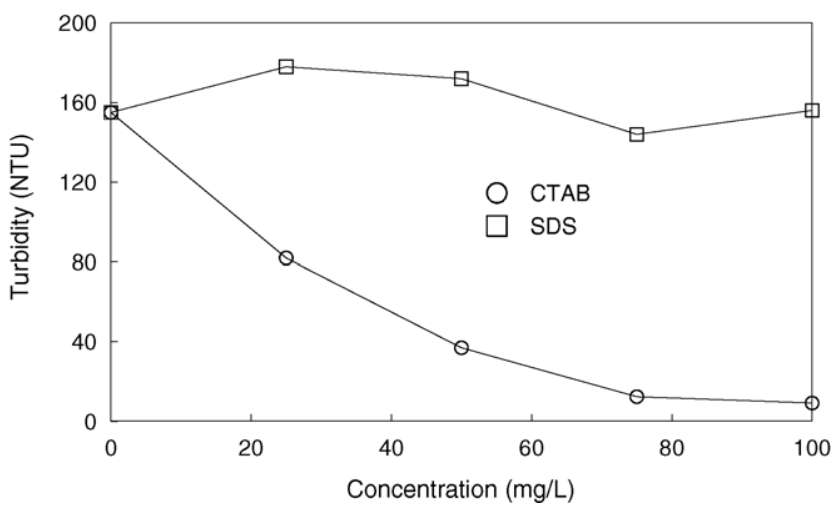

Fig. 1. Variation of the residual turbidity after ECF process with the concentration of surfactants in two different surfactants systems (initial turbidity $=155 \mathrm{NTU}, Q_{\mathrm{e}}=1440 \mathrm{CL}^{-1}$, reaction time $=5 \mathrm{~min}$, flotation $/$ sedimentation time $=3 \mathrm{~min}$ ).

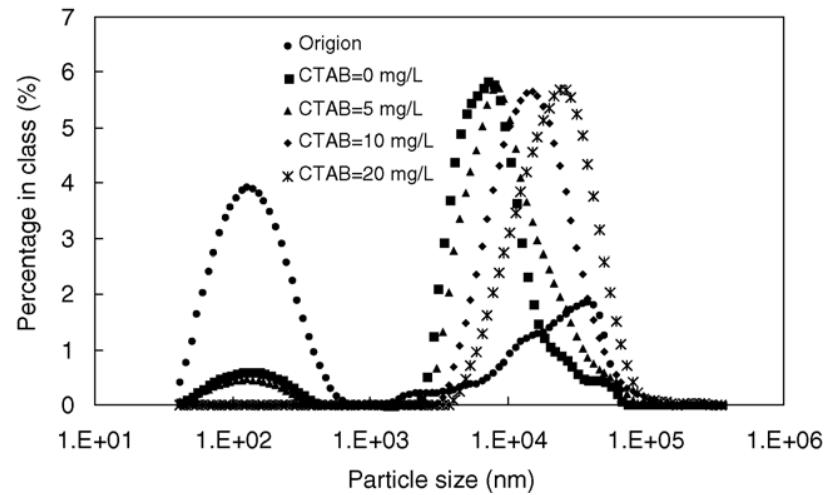

Fig. 2. Particle size distribution of the CMP wastewater before and after ECF reaction with various CTAB concentrations (initial turbidity $=155 \mathrm{NTU}, Q_{\mathrm{e}}=2880 \mathrm{CL}^{-1}$, reaction time $=10 \mathrm{~min}$, flotation $/$ sedimentation time $=30 \mathrm{~min}$ ).

results could also be attributed to the electrostatic interactions between positive CTAB ions and the negatively charged silica particles render the latter hydrophobic and facilitate flotation reaction.

Fig. 2 illustrates the particle size distribution of the CMP wastewater before and after ECF reaction with various $\mathrm{CTAB}$ concentrations. Most of the particles in the original wastewater were distributed in the range between 50 and $500 \mathrm{~nm}$. After the ECF process, most of the particles were distributed between 2 and $100 \mu \mathrm{m}$. Moreover, the particle size increased with increasing $\mathrm{CTAB}$ concentration. This phenomenon confirms the above inference that the addition of CTAB causes particle aggregation and stabilizes the floc.

Sludge production is a serious problem for coagulation processes involving aluminum ions. Sludge may comprise over $20 \%$ of the solution volume in the EC process [10,11]. Fig. 3 demonstrates the photograph image of the sludge form in the ECF systems with $5 \mathrm{mg} \mathrm{L}^{-1}$ of CTAB and without $\mathrm{CTAB}$. Clearly, the volume of sludge $\left(V_{\mathrm{s}}\right)$ in the system containing CTAB was significantly less than in the system without CTAB. Fig. 4 illustrates the variation $V_{\mathrm{s}} / V$ with $\mathrm{CTAB}$ concentration in the ECF process. The $V_{\mathrm{s}} / V$ ratio reduced from 54.5 to $31.5 \%$ as the CTAB concentration rose from 0 to $5 \mathrm{mg} \mathrm{L}^{-1}$. Moreover, most of the volume of sludge in the system containing CTAB was occupied by hydrogen gas. Therefore, the volume of sludge was very easy to be reduced.

Fig. 3 also reveals that all of the sludge in the system with CTAB floated to the top of the solution, while in the system without CTAB, some of the sludge settled at the bottom and some floated at the top of the solution. This phenomenon implies that adding CTAB can not only shrink the sludge volume but also can reduce the separation time of solid and liquid because the retention time for flotation is much less than for sedimentation. Fig. 5 shows the variation of the residual turbidity with sedimentation/flotation time in solutions with different concentrations of CTAB. The relationship between the residual turbidity and the flotation/sedimentation time in- 
(A)

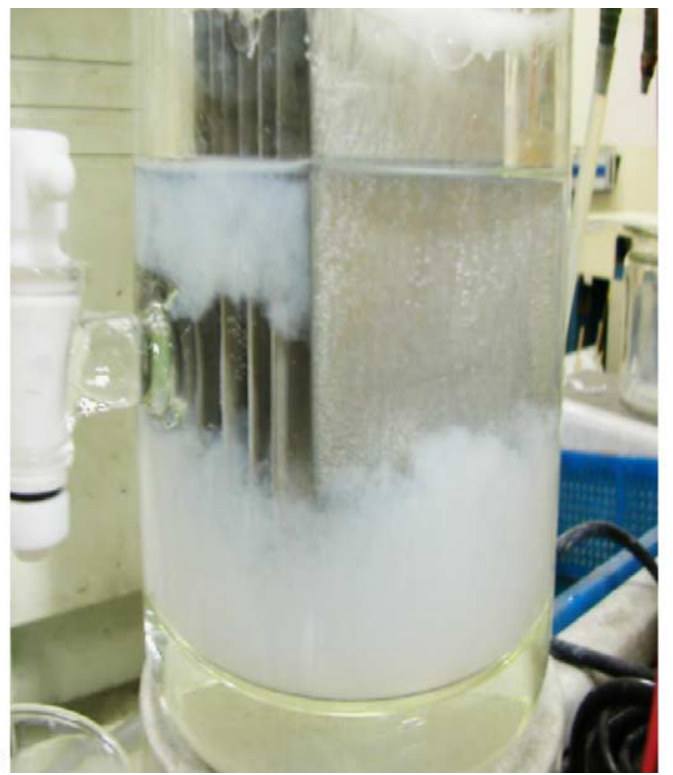

(B)

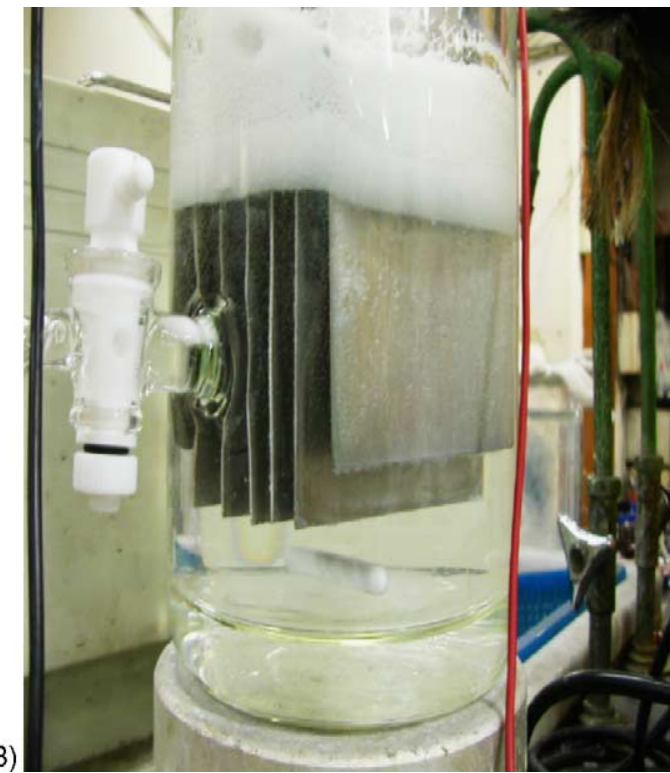

Fig. 3. Photograph images of the sludge form in the ECF systems containing $5 \mathrm{mg} \mathrm{L}^{-1}$ of CTAB and containing no CTAB. (A) No CTAB (B) $5 \mathrm{mg} \mathrm{L}^{-1}$ of $\mathrm{CTAB}$ (initial turbidity $=155 \mathrm{NTU}, Q_{\mathrm{e}}=2880 \mathrm{C} \mathrm{L}^{-1}$, reaction time $=10 \mathrm{~min}$, flotation $/$ sedimentation time $=30 \mathrm{~min}$ ).

dicated the settling or flotation time required for the systems with various CTAB concentrations. The residual turbidity in the system without CTAB remained over $10 \mathrm{NTU}$ until the settling time was over $20 \mathrm{~min}$. However, the residual turbidity in the system with CTAB dropped to less than 10 NTU as the flotation time was over $1 \mathrm{~min}$. This fact reveals that the system without CTAB required approximately $20 \mathrm{~min}$ for flocs sedimentation, but the flotation time required for achieving an ideal turbidity level in the solution containing CTAB was only $1 \mathrm{~min}$.

These phenomena can result from the hydrophobic nature of hydrogen gas. As mentioned earlier, most of the hydrogen bubbles generated from the cathode in the solution without CTAB are combined and then lost to the atmosphere. However, owing to the electric repulsion between bubbles caused by the positive charged CTAB molecule adsorbed on the surface of the bubbles, the hydrogen bubbles in the sys-

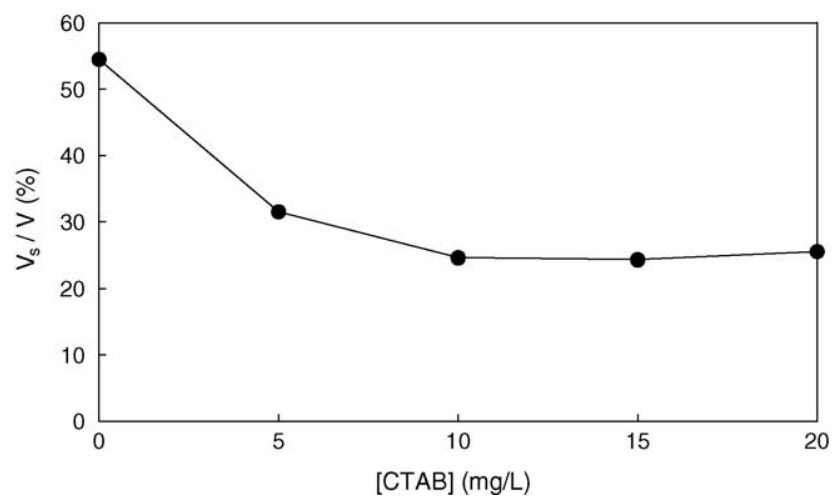

Fig. 4. Variation of the sludge percentage of the solution $\left(V_{\mathrm{s}} / V\right)$ with $\mathrm{CTAB}$ concentration (initial turbidity $=155 \mathrm{NTU}, Q_{\mathrm{e}}=2880 \mathrm{CL} \mathrm{L}^{-1}$, reaction time $=10 \mathrm{~min}$, flotation $/$ sedimentation time $=30 \mathrm{~min}$ ). tem containing CTAB failed to combine. So most bubbles did not lose to the atmosphere and can aggregate with the flocs. Moreover, finer bubbles have larger surface area. Consequently, all the floc in the system containing CTAB can be removed by flotation.

According to above results, it can be concluded that the surfactant enhances the performance of ECF through two phenomena. First, although no direct evidence is provided regarding bubbles size, it is possible that finer bubbles and larger surface area resulting from CTAB addition, along with inhibiting recombination of hydrogen gas, that contribute to enhanced flotation efficiency and kinetics. Second, adding the surfactant with opposite charge of the particle increases the attachment force between the bubble and particle and makes the particles hydrophobic. Therefore, the CTAB was employed not only as a frother, but also as a collector in the ECF process.

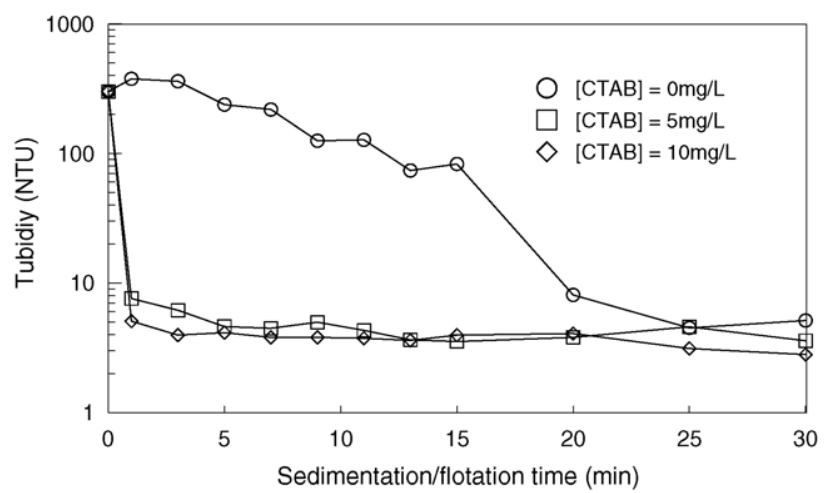

Fig. 5. Variation of turbidity with flotation/sedimentation time in solutions with different concentrations of CTAB ("flotation/sedimentation time" was defined as the certain time intervals following the completion of the ECF process; initial turbidity $=155 \mathrm{NTU}, Q_{\mathrm{e}}=2880 \mathrm{CL}^{-1}$, reaction time $=10 \mathrm{~min}$ ). 


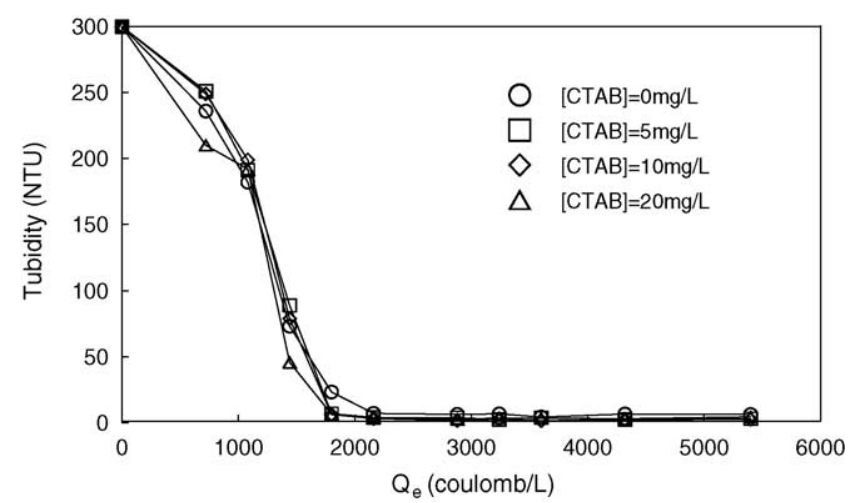

Fig. 6. The effect of $Q_{\mathrm{e}}$ and CTAB concentration on the residual turbidity (initial turbidity $=155 \mathrm{NTU}$, reaction time $=10 \mathrm{~min}$, flotation $/$ sedimentation time $=30 \mathrm{~min}$ ).

\subsection{Effects of charge loading applied}

The charge loading applied $\left(Q_{\mathrm{e}}\right)$ is defined as the charge applied per liter of solution (Eq. (3)),

$Q_{\mathrm{e}}=\frac{n I t}{V}$

Fig. 6 plots the effect of $Q_{\mathrm{e}}$ and CTAB concentration on the residual turbidity. The residual turbidity dropped with increasing $Q_{\mathrm{e}}$, and the minimum $Q_{\mathrm{e}}$ for $90 \%$ turbidity removal was around $2000 \mathrm{C} \mathrm{L}^{-1}$, and appeared unaffected by CTAB concentration. According to Faraday's Law, the concentration of $\mathrm{Al}(\mathrm{III})$ ions released from anodes can be calculated using Eq. (4),

$$
\left[\mathrm{Al}^{3+}\right]=\frac{Q_{\mathrm{e}}}{Z F}, \quad Z=3 \text { for } \mathrm{Al}(\mathrm{III})
$$

Combining Faraday's Law and the ideal gas law yields the volume of hydrogen gas generated from the cathode $\left(V_{\mathrm{H}_{2}}\right)$, provided by Eq. (5),

$V_{\mathrm{H}_{2}}=\frac{V R T Q_{\mathrm{e}}}{Z F P}, \quad Z=2$ for $\mathrm{H}_{2}$

The particles of the CMP wastewater are removed by coagulation of $\mathrm{Al}(\mathrm{III})$ ions and flotation of hydrogen gas, and thus the residual tubidity naturally declines with increasing $Q_{\mathrm{e}}$.

The dissolved Si can be removed by co-precipitation reaction of $\mathrm{Al}(\mathrm{III})$ ions. Co-precipitation occurs upon mixing of aluminum hydroxide and silicic acid (Eq. (6)) [17,18].

$$
2 \mathrm{Al}(\mathrm{OH})_{3}+x \mathrm{Si}(\mathrm{OH})_{4} \rightarrow \mathrm{Al}_{2} \mathrm{O}_{3} x \mathrm{SiO}_{2}+(2 x+3) \mathrm{H}_{2} \mathrm{O}
$$

Fig. 7 displays the variation of the residual dissolved Si concentration $\left([\mathrm{Si}]_{\mathrm{D}}\right)$ with $Q_{\mathrm{e}}$ in the solutions containing various concentrations of CTAB. The $[\mathrm{Si}]_{\mathrm{D}}$ decreased with increasing $Q_{\mathrm{e}}$. The minimum $Q_{\mathrm{e}}$ for $90 \%[\mathrm{Si}]_{\mathrm{D}}$ removal was approximately $700 \mathrm{C} \mathrm{L}^{-1}$ and was not influenced by CTAB concentration. Notably, the minimum $Q_{\mathrm{e}}$ for $90 \%[\mathrm{Si}]_{\mathrm{D}}$ removal is significantly less than the minimum $Q_{\mathrm{e}}$ for $90 \%$ turbidity

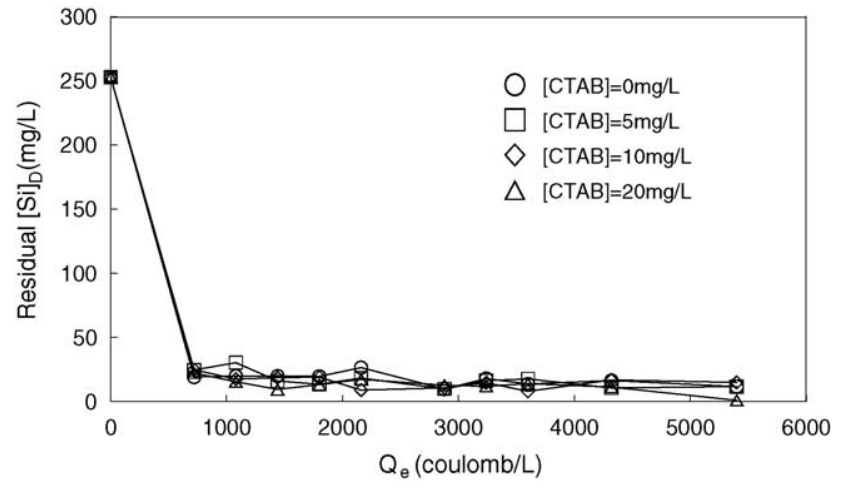

Fig. 7. The effect of $Q_{\mathrm{e}}$ and CTAB concentration on the residual [Si $]_{\mathrm{D}}$ (initial $[\mathrm{Si}]_{\mathrm{D}}=253 \mathrm{mg} \mathrm{L}^{-1}$, reaction time $=10 \mathrm{~min}$, flotation $/$ sedimentation time $=30 \mathrm{~min})$.

removal. Consequently, only the minimum $Q_{\mathrm{e}}$ required for turbidity removal needs to be considered in the ECF process.

\subsection{Concentration of residual surfactant}

Surfactant is also a pollutant in industrial wastewater. Therefore, residual CTAB concentration is considered in this study. Surfactant is a source of TOC. Since very little TOC existed in the original wastewater, as shown in Table 1, the TOC can be employed as an indictor to estimate the residual CTAB concentration [19]. Fig. 8 illustrates the variation of CTAB concentration with TOC. Moreover, Eq. (7) expresses the linear regression equation of the CTAB concentration versus TOC, as follows:

$[\mathrm{CTAB}]=2.23 \mathrm{TOC}, \quad R^{2}=0.996$

It is notable that the theoretical TOC per unit of CTAB $(0.627)$ is higher than the experimental one (0.448). This fact should be due to the incomplete oxidation during the digestion procedure in the TOC analyzer.

Fig. 9 shows the variation of the CTAB removal with $Q_{\mathrm{e}}$ in various solutions containing different initial CTAB concentrations. Pervious literatures have stated that the surfactants can be removed by flotation [20-23]. As mentioned earlier, the generation amount of hydrogen gas is proportional to the $Q_{\text {e }}$. Thus, the residual CTAB concentration deceased with

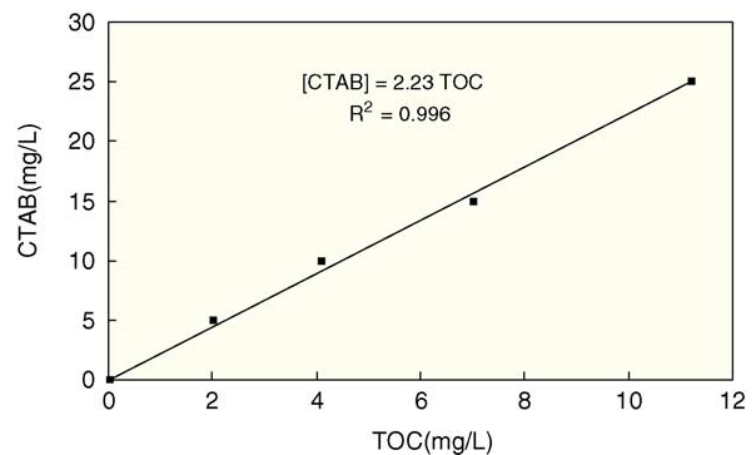

Fig. 8. Variation of CTAB concentration with TOC. 


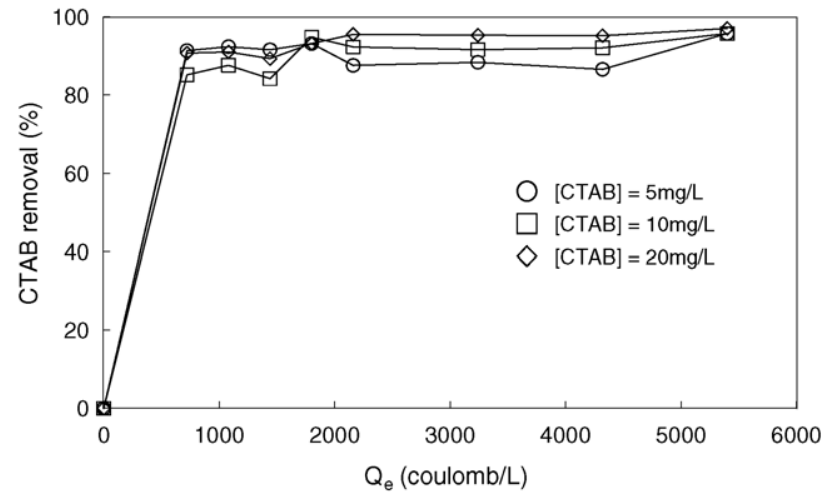

Fig. 9. Variation of the CTAB removal with $Q_{\mathrm{e}}$ in various solutions containing different initial $\mathrm{CTAB}$ concentrations (reaction time $=10 \mathrm{~min}$, flotation $/$ sedimentation time $=30 \mathrm{~min}$ ).

the increase of $Q_{\mathrm{e}}$. The CTAB removals in all solutions were over $90 \%$ and the residual CTAB concentrations in all solutions were below $1 \mathrm{mg} \mathrm{L}^{-1}$ once $Q_{\mathrm{e}}$ exceeded $1000 \mathrm{CL}^{-1}$. This fact indicates that no CTAB pollution problem existed after the ECF process and should result from the adsorption of CTAB on the surface of the silica and hydrogen bubbles.

\section{Conclusion}

ECF process with the addition of CTAB can effectively treat the CMP wastewater. The CTAB was employed not only as a frother but also as a collector in the process. The concentration of CTAB required to achieve idea flotation performance was below $20 \mathrm{mg} \mathrm{L}^{-1}$. Removal of turbidity and dissolved Si exceeded $90 \%$ given $Q_{\mathrm{e}}$ over $2000 \mathrm{CL}^{-1}$ with $5 \mathrm{mg} \mathrm{L}^{-1}$ of CTAB. The sludge volume and the settling time were significantly less in the solution containing CTAB than in that without CTAB. No CTAB pollution problem exists after the ECF process.

\section{Acknowledgements}

The authors would like to thank the National Science Council of the Chinese Taiwan for financially supporting this research under Contract No. NSC 92-2211-E-002-028.

\section{References}

[1] J.H. Golden, R. Small, L. Pagan, C. Shang, S. Raghavan, Evaluating and treating CMP wastewater, Semicond. Int. 23 (2000) 92-103.

[2] G. Corlet, Treating water reuse for chemical mechanical polishing, Solid State Technol. 43 (2000) 182-187.

[3] R. Lo, S.L. Lo, A pilot plant study using ceramic membrane microfiltration, carbon adsorption and reverse osmosis to treat CMP (chemical mechanical polishing) wastewater, Water Sci. Tech. 4 (1) (2004) 111-118.

[4] G.H. Chen, X.M. Chen, P.L. Yue, Electrocoagulation and electroflotation of restaurant wastewater, J. Environ. Eng. 126 (2000) 858-863.

[5] J.Q. Jiang, N. Graham, C. Andre, G.H. Kelsall, N. Brandon, Laboratory study of electro-coagulation-flotation for water treatment, Water Res. 36 (2002) 4064-4078.

[6] M.Y.A. Mollah, R. Schennach, J.R. Parga, D.L. Cocke, Electrocoagulation (EC)—science and applications, J. Hazard. Mater. B84 (2001) 29-41.

[7] F. Shen, X. Chen, P. Gao, G. Chen, Electrochemical removal of fluoride ions from industrial wastewater, Chem. Eng. Sci. 58 (2003) 987-993.

[8] C.Y. Hu, S.L. Lo, W.H. Kuan, Effects of co-existing anions on fluoride removal in electrocoagulation (EC) process using aluminum electrodes, Water Res. 37 (2003) 4513-4523.

[9] B.M. Belongia, P.D. Haworth, J.C. Baygents, S. Raghvan, Treatment of alumina and silica chemical mechanical polishing waste by electrodecantation and electrocoagulation, J. Electrochem. Soc. 146 (1999) 4124-4130.

[10] L.L. Chen, S.H. Lin, Electrocoagulation of chemical mechanical polishing (CMP) wastewater from semiconductor fabrication, Chem. Eng. J. 95 (2003) 205-211.

[11] C.L. Lai, S.H. Lin, Treatment of chemical mechanical polishing wastewater by electrocoagulation: system performances and sludge settling characteristics, Chemosphere 54 (2004) 235-242.

[12] K.A. Matis, P. Mavros, Recovery of metals by ion flotation from dilute aqueous solution, Sep. Purif. Methods 20 (1991) 1-48.

[13] M.C. Lin, J.C. Liu, Adsorbing colloid flotation of As(V)—feasibility of utilizing steaming current detector, Sep. Sci. Technol. 31 (1996) $1629-1641$.

[14] C.J. Huang, J.C. Liu, Precipitation flotation of fluoride-containing wastewater from semi-conductor manufacture, Water Res. 33 (5) (1999) 3403-3412.

[15] T.C. Chuang, C.J. Huang, J.C. Liu, Treatment of semiconductor wastewater by dissolved air flotation, J. Environ. Eng. 128 (2002) 974-980.

[16] L. Alexandrova, R.J. Pugh, F. Tiberg, L. Grigorov, Confirmation of the heterocoagulation theory of flotation, Langmuir 15 (1999) 7464-7471.

[17] D.L. Gallup, Aluminum silicate scale formation and inhibition: scale characterization and laboratory experiments, Geothermics 26 (1997) 483-499.

[18] D.L. Gallup, Aluminum silicate scale formation and inhibition (II): scale solubilities and laboratory and field inhibition tests, Geothermics 27 (1998) 485-510.

[19] G. Lissens, J. Pieters, M. Verhaege, L. Pinoy, W. Verstraete, Electrochemical degradation of surfactants by intermediates of water discharge at carbon-based electrodes, Electrochim. Acta 48 (2003) $1655-1663$.

[20] S. Chen, M.B. Timmons, D.J. Aneshansley, J.J. Bisogni Jr., Modeling surfactant removal in foam fractionation. I. Theoretical analysis, Aquacult. Eng. 13 (1994) 163-181.

[21] S. Chen, M.B. Timmons, D.J. Aneshansley, J.J. Bisogni Jr., Modeling surfactant removal in foam fractionation. II. Experimental investigations, Aquacult. Eng. 13 (1994) 183-200.

[22] K. Kumpabooth, J.F. Scamehorn, S. Osuwan, J.H. Harwell, Surfactant recovery from water using foam fractionation: effect of temperature and added salt, Sep. Sci. Tech. 34 (1999) 157-172.

[23] S. Boonyasuwat, S. Chavadej, P. Malakul, J.F. Scamehorn, Anionic and cationic surfactant recovery from water using a multistage foam fractionator, Chem. Eng. J. 93 (2003) 241-252. 